\title{
Evidence of CNS impairment in HIV infection: clinical, neuropsychological, EEG, and MRI/MRS study
}

M J G Harrison, S P Newman, M A Hall-Craggs, C J Fowler, R Miller, B E Kendall, M Paley, I Wilkinson, B Sweeney, S Lunn, S Carter, I Williams

\begin{abstract}
Objectives-To identify by clinical examination, EEG, MRI, and proton spectroscopy, and neuropsychological assessment the prevalence of signs of CNS involvement in patients infected with HIV, and to relate such findings to the evidence of immunosuppression.

Methods-The design was a cross sectional analysis of a cohort of male patients with infected HIV with an AIDS defining diagnosis or low CD4 count $(<350)$, and seropositive asymptomatic subjects, both groups being followed up in a longitudinal study. Control groups consisted of seronegative subjects from the same genitourinary medicine clinics.

Results-This report sets out the cross sectional findings at the seventh visit in the longitudinal study. Patients with AIDS had more signs of neurological dysfunction, poorer performance on a neuropsychological test battery, were more likely to have an abnormal EEG, and to have abnormalities on MRI. They more often had cerebral atrophy, abnormal appearing white matter, , and abnormal relaxometry and spectroscopy. There was little evidence of abnormality in seropositive people who had a CD4 count $>350$ compared with seronegative people from a similar background.

Conclusions-Detailed testing failed to disclose significant CNS impairment without immunosuppression in men infected with HIV. Findings from MRI and magnetic resonance spectroscopy (MRS) correlated with those of the neurological examination and neuropsychogical assessment. A combination of such assessments offers a simple surrogate for studies of CNS involvement in HIV disease. (f Neurol Neurosurg Psychiatry 1998;65:301-307)
\end{abstract}

Keywords: HIV infection; CNS impairment; magnetic resonance imaging; neuropsychological test battery

In the first definitive review of neurological disorders related to HIV, Snider et al ${ }^{1}$ described 18 patients with an encephalitic illness characterised by cognitive and behavioural changes. Initially it was thought that this picture was due to cytomegalovirus infection, and therefore another example of an opportunistic process due to immunosuppression (along with cryptococcal meningitis, toxoplasma abscesses, pro- gressive multifocal leukoencephalopathy, and cerebral lymphoma). It became clear, however, that such cognitive changes are more commonly related to HIV infection itself. The precise mechanism of the changes remains incompletely understood. The neuropathological accompaniments of the HIV associated dementia complex include an encephalitis with macrophages infected with HIV forming multinucleated giant cells, leukoencephalopathy with myelin pallor and astrocytosis, and poliodystrophy with neuronal loss and abnormalities of neuronal dendrites. There is not a simple one to one relation between any pathological finding and the presence of dementia, however, with occasional patients showing a complete dissociation-for example, cognitive loss with histological normality or encephalitis with clinical normality. ${ }^{2}$ None the less, multinucleated giant cells, ${ }^{3}$ viral load, ${ }^{4}$ markers of macrophage activation, ${ }^{5}$ and the presence of cytokines such as tumour necrosis factor $(\mathrm{TNF} \alpha)$ in the brain ${ }^{6}$ all show a positive relation with the incidence or severity of dementia. Neuronal counts in the cortex do not. $^{7}$

In the clinical investigation of patients with dementia, neuroimaging similarly discloses a range of changes. Cerebral atrophy, changes in white matter thought to reflect leukoencephalopathy or encephalitis, and spectroscopic abnormalities held to parallel neuronal dysfunction have all been described. ${ }^{8-10}$ Seronegative and asymptomatic seropositive people in the Multicentre AIDS Cohort Study (MACS) had the same prevalence of minor white matter abnormalities or atrophy. Atrophy and more clear cut leukoencephalopathy became apparent in AIDS. ${ }^{11}$

Changes in EEG are non-specific but increasingly common in those with focal infections or lymphomas and in those with dementia. ${ }^{12}$ The MACS study ${ }^{13}$ has reported no difference in the incidence of EEG abnormalities in asymptomatic subjects when compared with seronegative controls, but Parisi et $a l^{14}$ reported that EEG abnormality might be a predictor of CNS involvement.

Neuropsychological assessment has been used at the bedside to document the pattern and extent of dementia, ${ }^{15}$ and in a research context to detect the earliest signs of departure from normal. ${ }^{16}$ At first the data were interpreted as disclosing signs of cognitive impairment in the asymptomatic stages of HIV infection before the onset of immunosuppression. ${ }^{17}$ in revised form 20 January 1998

Accepted 17 February 1998 
Table 1 Neuropsychological test battery

At each assessment
Letter cancellation:
Rey auditory verbal learning test
Trail making A and B
Non-verbal recognition memory test $1^{\star}$
Non-verbal recognition memory test $2^{\star}$
2 Choice reaction time
Facial recognition test $\dagger$
Wisconsin card sort $\ddagger$
Symbol digit substitution $₫$
Purdue pegboard
Controlled oral word association test
WAIS-R block design
At first assessment only:
National adult reading test (NART)
WAIS-R vocabulary
WAIS-R picture completion
${ }^{\star}$ For details see ${ }^{21} ; \dagger^{22} ; \ddagger^{23} ; \mathbb{\complement}^{24}$.

Later larger series including that of the MACS group ${ }^{18}$ and our own ${ }^{16}$ tended to refute the earlier claim. A review of the published literature highlighted the fact that the largest studies showed little or no evidence of subclinical cognitive deficit in non-immunosuppressed people. ${ }^{19}$

In 1987 a cohort study began at the Middlesex Hospital which aimed to identify whether subclinical abnormalities compatible with first signs of a dementia illness were detectable in patients infected with HIV. The timing of the emergence of such problems and its relation to markers of immunosuppression (CD4, $\beta 2$ microglobulin) and to systemic disease (clinical diagnoses, $\mathrm{Hb}$ concentration) were sought. The coincidence of neuropsychological, EEG, neuroimaging, and clinical criteria was a particular interest to see which, if any, parameters might be usable as surrogate markers for the dementia illness. Any such surrogate would clearly be useful in interventional trials, perhaps reducing the numbers of subjects or duration of follow up needed to know whether damaging changes in the CNS could be delayed or prevented.

\section{Methods}

SUBJECTS

Ninety five seropositive and 32 seronegative men were originally recruited into the neurological study. None had neurological problems when recruited but 15 had an AIDS defining diagnosis. All recruited subjects were homosexual or bisexual and had probably seroconverted in 1983-4 to judge by point prevalence studies in the genitourinary medicine clinics at the Middlesex Hospital. The seronegative subjects were partners of seropositive recruits or others attending the genitourinary medicine clinic.

During the longitudinal follow up study (1987-96) 31 subjects were lost due to moving away, withdrawal of consent, deaths from AIDS etc. Numbers were maintained by further recruitment from the genitourinary medicine service of 57 further subjects of which 46 were seropositive and 11 seronegative.

Subjects attended twice a year and were seen by the research neurologist, research nurse, and psychologist. They also underwent MRI and spectroscopy and had a routine EEG recording. Blood was taken from the HIV seronegative and seropositive subjects for HIV status, haemoglobin, white blood cell count, total lymphocyte and CD4 count, platelet count, and $\beta 2$ microglobulin. Center for Disease Control and Prevention (CDC) status was noted and therapy with any antiretroviral drugs documented. Alcohol and recreational drug use were also recorded.

The neurologist carried out a routine conventional neurological examination, the results of which were transferred to proformas. The clinician summarised the clinical findings with a comment on whether the patient showed any (neurological) abnormality, and categorised these into encephalopathy, cerebellar deficit, myelopathy, neuropathy, and myopathy, using the American Academy of Neurology criteria $^{20}$ These include definite, probable, and possible categories in the case of encephalopathy and myelopathy.

The subjects then carried out a battery of cognitive tests and mood assessments (table 1). To determine relative performance $\mathrm{z}$ scores were calculated from the group mean for the seronegative subjects. To control for practice effect the performance of seropositive subjects was compared with the seronegative subjects who had had the same number of prior assessments. Seropositive subjects were identified as having a neuropsychological deficit when their performance in at least two tests was $0.5 \mathrm{SD}$ or more below the seronegative mean. This small difference was chosen to detect any small changes in the asymptomatic subjects.

Brain MRI involved obtaining quantitative T1/T2 maps, relaxometry, ${ }^{25}$ calculating brain and CSF volumes by the CLASS segmentation technique, and obtaining proton spectra from a parieto-occipital $8 \mathrm{ml}$ voxel placed predominantly over white matter behind the trigone on the dominant side (the opposite side was used if a focal lesion contaminated the first site). The images were reported qualitatively by two radiologists blind to the clinical circumstances and recorded on a proforma. The opinion was given as to whether the images were abnormal, showed ventricular and/or sulcal dilatation, and whether the white matter showed discrete or diffuse hyperintensity on T2 weighted images. Volumes and proton spectra were calculated by in house programs described elsewhere, ${ }^{1026}$

Routine 20 lead EEGs were recorded (neuromapper) including a period of 3 minutes of hyperventilation. These too were reviewed without access to the clinical circumstances by a consultant clinical neurophysiologist and recorded as abnormal or not, dependent on the abundance of intermediate (theta) or slow (delta) activity and the stability and frequency of the alpha rhythm. A 1-5 grading scale was utilised. Grade 1 (normal) contained an alpha rhythm over $8 \mathrm{~Hz}$ or generalised fast activity but no slow activity, sharp waves, or spikes. Grade 2 (borderline normal) records were similar but might have minor transients or an equivocal excess of theta activity. Grade 3 (mildly abnormal) referred to records with occasional sharp waves, or asymmetry, or a mild excess of slow activity. Grade 4 (moder- 
Table 2 Age distribution in study population

\begin{tabular}{llll}
\hline & Seronegative & Seropositive & AIDS \\
\hline $\mathrm{n}$ & 30 & 30 & 56 \\
Age (y, mean (SD)) & $42.4(9.2)$ & $38.4(5.5)$ & $38.0(7.6)$ \\
Range & $27-61$ & $27-52$ & $28-57$ \\
\hline
\end{tabular}

Table 3 Haematological variables (SD)

\begin{tabular}{llll}
\hline & Seronegative & Seropositive & AIDS \\
\hline $\mathrm{n}$ & $(30)$ & $(28-30)$ & $(55-56)$ \\
$\mathrm{Hb}(\mathrm{g} / \mathrm{l})$ & $15.2(0.85)$ & $14.2(0.9)$ & $12.9(1.8)^{\star}$ \\
$\mathrm{MCV}\left(\mu \mathrm{m}^{3}\right)$ & $92.1(4.6)$ & $92.1(7.6)$ & $98.2(10.2) \dagger$ \\
$\mathrm{WBC}\left(10^{3} / \mathrm{mm}^{3}\right)$ & $6.4(1.5)$ & $5.5(1.8)$ & $3.99(1.8) \dagger$ \\
Lymphocytes $\left(10^{3} / \mathrm{mm}^{3}\right)$ & $1.9(0.47)$ & $2.1(0.67)$ & $1.27(0.7) \dagger$ \\
$\mathrm{CD} 4\left(10^{3} / \mathrm{mm}^{3}\right)$ & $0.84(0.25)$ & $0.49(0.21)$ & $0.16(0.14)^{\star}$ \\
Platelets $\left(10^{3} / \mathrm{mm}^{3}\right)$ & $242(51)$ & $213(58)$ & $197(67) \ddagger$ \\
$\beta 2$ Microglobulin $(\mathrm{mg} / \mathrm{l})$ & $1.79(0.85)$ & $2.66(0.7)$ & $3.36(1.1)^{\star}$ \\
\hline
\end{tabular}

${ }^{\star}$ Differences between all three groups $\mathrm{p}<0.001$.

$\dagger$ Differences between AIDS and each of the other groups $\mathrm{p}<0.001$.

$\ddagger$ Differences between AIDS and seronegative group only $\mathrm{p}<0.001 . \mathrm{MCV}=$ mean cell volume; WBC=white blood cell count.

ately abnormal) records had a dominant rhythm below $8 \mathrm{~Hz}$, marked asymmetry, periodic sharp waves, or moderate slowing. Grade 5 (markedly abnormal) additionally showed marked slowing or spikes. For some analyses the findings were collapsed into a normal (grades 1or 2) and abnormal (grades 3-5) categories.

This paper reports the findings at the visits that took place between 1994 and 1995, five subjects were omitted from the study as they proved to have neurological disorders which affected the results of their assessments. Thus their CNS findings were attributable to cerebral palsy, head injury, and toxoplasmosis, and neuromuscular problems to surgery, herpes zoster radiculopathy, and a damaged knee joint (quadriceps wasting). Not all subjects completed all parts of the assessments so the total numbers referred to in the results differ. The number providing data in each assessment are indicated in the tables. Subjects were initially categorised clinically as seropositive asymptomatic (CDC II-III), and AIDS (CDCIV) using the 1986 CDC criteria that did not include CD4 counts. For the current comparisons asymptomatic subjects with a CD4 count below 200 were included in the AIDS category. Statistical analysis was performed on SPSS-X with $\chi^{2}$ analysis used for categorical data and

Table 4 Neurological findings

\begin{tabular}{llllll}
\hline & Seronegative & Seropositive & AIDS & $\chi^{2}$ & p Value \\
\hline $\mathrm{n}$ & $(29)$ & $(28)$ & $(50)$ & & \\
Any abnormality & 9 & 13 & 31 & 37.8 & 0.001 \\
Encephalopathy & 1 & 4 & 22 & 39.7 & 0.001 \\
Cerebellar deficit & 4 & 5 & 14 & 14.2 & 0.003 \\
Myelopathy & 1 & 5 & 13 & 20.4 & 0.001 \\
Neuropathy & 4 & 5 & 13 & 14.2 & 0.003 \\
\hline
\end{tabular}

Table 5 MRI evidence of atrophy

\begin{tabular}{|c|c|c|c|c|c|c|}
\hline & & Seronegative & Seropositive & AIDS & $\chi^{2}$ & $p$ Value \\
\hline \multicolumn{7}{|l|}{ Reported: } \\
\hline $\mathrm{n}$ & & 30 & 30 & 56 & & \\
\hline Wide sulci & & 6 & 1 & 12 & 16 & 0.001 \\
\hline Large ventricles & & 6 & 3 & 12 & 13.1 & 0.006 \\
\hline \multicolumn{5}{|l|}{ Calculated: } & $\mathrm{F}$ & \\
\hline $\mathrm{n}$ & & 25 & 25 & 52 & & \\
\hline CSF/ICV (mean & $(\mathrm{SD}))$ & $0.13(0.04)$ & $0.12(0.03)$ & $0.14(0.05)$ & 4.19 & 0.007 \\
\hline
\end{tabular}

analysis of variance (ANOVA) when appropriate followed by post hoc analysis pairwise comparisons (Sheffe) for continuous data.

The results of serial assessments over time will form the basis of a further report.

\section{Results}

At the time of the 1994-5 HIV study routine visit, there were 30 seronegative subjects, 39 asymptomatic HIV positive men, and 47 with AIDS. No seronegative subjects had a CD4 count below 200, whereas nine asymptomatic seropositive subjects did together with 33 with a clinical diagnosis of AIDS. For all the results to be presented the nine seropositive but asymptomatic subjects with low CD4 counts were recoded as AIDS cases. No differences were found in the ages of the groups (table 2).

The mean (SD) CD4 counts, haemoglobin, mean corpuscular volume (MCV), white blood count, lymphocyte platelet counts, and $\beta 2$ microglobulin concentrations for the HIV groups are shown in table 3.

The patients with AIDS predictably had the lowest counts, but the highest MCV and $\beta 2$ microglobulin results. This represents evidence of immunosuppression, marrow suppression, and probably in the case of the MCV, the use of AZT in therapy.

The neurologists' examination proforma was available and complete for all but one seronegative, two seropositive, and six AIDS patients. An abnormality was recorded most often in the AIDS group (table 4). Some subjects had evidence of more than one abnormality (for example, encephalopathy and neuropathy). A significant difference with increased prevalence of detectable abnormality in the AIDS group was found for any abnormality, encephalopathy, and myelopathy (table 4). This remained significant for each of these categories $(p=0.02$; $\mathrm{p}=0.001$, and $\mathrm{p}=0.03$ respectively) when the comparison was made between the AIDS and seronegative groups.

Brain MRI reports indicated abnormalities in $40.7 \%$ of the study population (17 of 30 seronegatives, 16 of 31 seropositives, and 36 of 57 patients with AIDS $\left(\chi^{2} 33.8, p<0.001\right)$ ). The prevalence of signs of atrophy in the patient groups is shown in table 5 together with the segmentation derived measure of atrophy, the ratio of CSF to intracranial volume (ICV=brain and CSF). Sulcal widening was diagnosed by the radiologists in six of 30 seronegative, one of 31 seropositive, and 12 of 57 patients with AIDS $(\mathrm{p}<0.001)$. They reported ventricular dilatation in six of 30 seronegative, three of 31 seropositive, and 12 of 57 patients with AIDS ( $\mathrm{p}=0.06)$. The calculated CSF/ICV ratio was greatest in the AIDS group (0.14). Thus with both methods of assessment there was evidence of a greater degree of atrophy in the patients with AIDS. Diffuse changes in white matter were recorded in four of $30(13 \%)$ seronegative high risk controls, six of 31 (19\%) asymptomatic patients infected with HIV, and 12 of $57(21 \%)$ patients with AIDS; a trend to borderline significance $(\mathrm{p}=0.07)$. 
Table 6 MR relaxometry

\begin{tabular}{lllll}
\hline & Seronegative & Seropositive & AIDS F value & p Value \\
\hline $\mathrm{n}$ & $16-19$ & $21-22$ & $24-25$ & \\
T2 frontal (1) & $68.8(4.1)$ & $67.9(4.5)$ & $68.2(3.3)$ & 10.62 \\
T2 parietal (1) & $74.2(5.4)$ & $72.9(6.1)$ & $71.7(7.9)$ & 5.81 \\
T2 occipital (1) & $78.2(4.2)$ & $79.5(4.0)$ & $81.1(8.2)$ & 6.06 \\
\hline Values are $\operatorname{mean}(\mathrm{SD})$ & & &
\end{tabular}

Table 8 Background for neuropsychological testing NART and education

\begin{tabular}{llll}
\hline & Seronegative & Seropositive & AIDS \\
\hline $\mathrm{n}$ & 29 & 39 & 47 \\
Age (y) & $41.7(9.1)$ & $38.2(5.0)$ & $38.0(7.8)$ \\
NART & $121.4(4.5)$ & $119.2(5.4)$ & $118.3(6.1)$ \\
Education (y) & $13.9(3.2)$ & $14.7(2.8)$ & $14.5(3.3)$ \\
\hline
\end{tabular}

Values are mean (SD).

Relaxometry showed significant bilateral abnormalities with lengthening of $\mathrm{T} 2$ in the AIDS patients in several regions $(p=0.001)$. $T 1$ values only differed in basal ganglia (not shown). For convenience only the left sided data are shown in table 6. Post hoc tests (Scheffe) indicated that T2 values in the AIDS group were significantly different from each of the other groups in the frontal, parietal, and basal ganglia regions. In the occipital region the AIDS group was found to be significantly different to the seropositive group.

Magnetic resonance spectroscopy (MRS) ratios showed a significant difference between the groups with a trend (non-significant) for a relative reduction in NAA peak in the AIDS group (table 7) in the subset tested. Too few seropositive asymptomatic subjects were tested for this comparison to be reliable.

There were no differences in years in education or in the NART full scale (1982) IQ estimate between the groups (table 8). Direct comparisons of test performance are therefore unconfounded with the potential influence of education or permorbid IQ on the test performance. The three groups' mean $\mathrm{z}$ scores (as calculated on the basis of the seronegative group's performance at the same visit, so matching the number of previous attempts at the same assessments) for each of the cognitive tests and for the total performance on the battery of tests was examined by ANOVA. Significant differences in performance were found between the groups on the trail making test B, Purdue pegboard, symbol digit test, and the total score for neuropsychological performance (table 9). Post hoc comparisons indicated that in all cases the AIDS group performed at a significantly poorer level than the other groups.

The EEG was interpreted as showing abnormality (grade 3-5) in four of $30(13 \%)$ seronegative subjects, two of $25(8 \%)$ asymptomatic HIV infected subjects, and 13 of 53

Table 7 MR spectroscopy

\begin{tabular}{llll}
\hline & Seronegative & Seropositive & AIDS \\
\hline $\mathrm{n}$ & 13 & 6 & 28 \\
$\mathrm{NAA} / \mathrm{NAA}+\mathrm{Cho}+\mathrm{Cr}$ & $0.54(0.04)$ & $0.50(0.03)$ & $0.52(0.05)$ \\
\hline $\mathrm{F}=3.75 \mathrm{p}=0.014$. & & & \\
Values are mean $(\mathrm{SD})$. & & &
\end{tabular}

(24.5\%) patients with AIDS, a trend of borderline significance.

COMPARISON OF RESULTS OF DIFFERENT

ASSESSMENTS

Among the seropositive persons, those diagnosed as having possible, probable, or definite neurological abnormality were more likely to show atrophy on MRI both by visual rating and measured volumes and also to perform below average (by $0.5 \mathrm{SD}$ ) on aspects of the Rey auditory memory test and on choice reaction time. Those considered to have encephalopathy (possible, probable, or definite) were also more likely to have atrophy and poorer performance on the Rey test, and neuropathy cases had more problems with the choice reaction time. The MRS and EEG ratings were not significantly associated with the clinical diagnostic rankings. Patients with encephalopathy had significantly lower haemoglobin, lymphocyte, and CD4 counts.

Subjects with an abnormal MRI report of any nature and more specifically relating to wide sulci had poorer results on trail making B, symbol digit, and aspects of the Rey test. Those with changes in white matter did significantly worse on trail making test $\mathrm{B}$, symbol digit, and the non-verbal memory tests. Those with an average $\mathrm{z}$ score for all the tests of $-0.5 \mathrm{SD}$ or below were more likely to have abnormalities of white matter on imaging $\left(\chi^{2}=7.1, \mathrm{p}=0.008\right)$.

As expected, the report of visually abnormal white matter correlated with quantification by relaxometry of T1 and T2 measurements in frontal parietal and occipital lobes ( $\mathrm{p}$ values $0.02-<0.001)$. Changes in white matter were not correlated with the finding of atrophy. Magnetic resonance spectroscopy disclosed a lower $\mathrm{NAA} /(\mathrm{NAA}+\mathrm{Cho}+\mathrm{Cr})$ ratio for those with abnormal appearing white matter $(0.52$ (SD $0.03 v 0.56$ (SD 0.04), $t=2.01, \mathrm{p}=0.048$ ). Such changes in white matter were not significantly associated with the neurological assessment findings, the EEG report of abnormality, or the level of CD4 count ( $<200$ or $>200)$.

In table 10 the frequency of abnormal findings in the three main assessments is shown for the different groups of subjects. In each case the data have been dichotomised. Any abnormality on the visual assessment of the MRI was taken as a "positive" result as was any possible, probable, or definite diagnosis of CNS abnormality by the clinician. In the case of the neuropsychological testing the overall mean z score was rated as abnormal if it fell $0.5 \mathrm{SD}$ below the composite mean of the seronegative group. When a subject failed to complete all the individual tests and no such score was available, their performance was considered abnormal if it fell below the mean score of the seronegative controls by 0.5 SD for six or more completed tests. As is clear from this simple tabulation only the immunocompromised patients with AIDS as a group showed an increased prevalence of evidence of CNS disease as witnessed by an abnormal evaluation in two or more assessments when compared with the seronegative controls $\left(\chi^{2} 5.24, \mathrm{p}<0.025\right)$. The AIDS group was also more likely to be scored 
Table 9 Results of neuropsychological testing

\begin{tabular}{llllll}
\hline & Seronegative & Seropositive & AIDS & F & p Value \\
\hline $\mathrm{n}$ & $25-30$ & $24-30$ & $45-56$ & & \\
Trails B & $0.03(1.0)$ & $0.22(0.58)$ & $-0.67(1.3)$ & 8.14 & 0.001 \\
Purdue pegboard & $0.13(0.88)$ & $0.06(0.89)$ & $-0.4(1.0)$ & 3.92 & 0.023 \\
Symbol digit & $0.004(0.9)$ & $-0.04(1.2)$ & $-0.65(1.4)$ & 3.7 & 0.03 \\
Total z score & $0.15(0.69)$ & $-0.07(0.57)$ & $-0.33(0.68)$ & 5.56 & 0.005 \\
\hline
\end{tabular}

* Significance between AIDS and each of the other groups.

Values are mean (SD).

Table 10 Number of assessments showing abnormality

\begin{tabular}{llllll}
\hline \multirow{5}{*}{ Patient group } & \multicolumn{2}{l}{ Number of assessments } \\
\cline { 2 - 6 } & 0 & 1 & 2 & 3 & $2 / 3$ \\
\hline SN & 12 & 14 & 6 & 0 & 6 \\
SP & 9 & 15 & 7 & 0 & 7 \\
AIDS & 12 & 23 & 19 & 7 & $26^{\star}$ \\
\hline
\end{tabular}

«Different from SN.

Criteria: MRI — any abnormality on visual rating; neurology — abnormality on clinical examination indicative of CNS change; neuropsychology - mean $\mathrm{z} \leqslant-0.5$, or $\geqslant 6$ tests with individual $\mathrm{z}$ scores $\leqslant 0.5$ if less than all tests completed.

$\mathrm{BL}=$ potential blood donors; $\mathrm{SN}=$ seronegative homosexual men; $\mathrm{SP}=$ seropositive homosexual men; AIDS=symptomatic or immunosuppressed patients.

as abnormal on two or more assessments than the seropositive patients $\left(\chi^{2} 3.55, \mathrm{p}<0.1\right)$. There were no significant differences in performance between the asymptomatic seropositive and seronegative groups.

\section{Discussion}

Neurological disease is a much feared, although usually late, complication of HIV infection. There is good evidence that HIV may enter the CNS at the time of seroconversion, ${ }^{27}$ and chronic CSF changes imply persistence of low grade infection. ${ }^{28} \mathrm{HIV}$ is detectable in the brain $^{29}$ and with polymerase chain reaction/ insitu hybridisation and immunocytochemistry most infected cells prove to be macrophages and microglia. A few astroglia also show evidence of infection. ${ }^{30}$ Although neuronal counts are low, ${ }^{31}$ neurons are apparently rarely if ever infected. Their dysfunction and morphological signs of damage with dendritic pruning $^{32}$ are therefore considered to be secondary effects of the microglial infection. Viral gene products may be released and have bystander effects. The HIV envelope protein Gp 120, for example, is cytotoxic to neurons in tissue culture, as is tat, which also up regulates HIV replication. The nef protein has also been incriminated as it shares some homology with scorpion neurotoxin. The products of activated macrophage metabolism are also potential causes of neuronal injury. Quinolinic acid, which is a breakdown product of tryptophan metabolism in macrophages, is raised in the CSF of demented patients and is neurotoxic. Arachidonic acid catabolites may also be raised in the CSF and leukotrienes and platelet activating factor can cause neuronal damage. ${ }^{33}$ Cytokines such as $\mathrm{TNF}^{6}$ are also considered to play a part in the myelin pallor and astrocytosis affecting cerebral white matter (HIV leukoencephalopathy) that is a common change found at postmortem in patients with AIDS. Oligodendrocytes are rarely infected.

The most characteristic pathological change in the brain of patients dying of AIDS is a multinucleated giant cell encephalitis. ${ }^{34}$ The multinucleated cells represent aggregations of HIV infected macrophages. Although the presence of HIV encephalitis is correlated with the severity of dementia the correspondence of clinical features and pathological appearances is weak. ${ }^{24}$ This evidence all points to a secondary effect of HIV infection in the pathogenesis of the dementia motor complex.

That immunodepression is important in the aetiology of the dementing illness is suggested by the evidence that cognitive changes are rare before an AIDS diagnosis is made. ${ }^{13}$ After a diagnosis of AIDS, dementia acrues at about $7 \%$ a year in longitudinal studies. ${ }^{35}$ The role of immunosuppression could either be to permit some as yet unidentified opportunistic infection (for which there is no definite neuropathological evidence), or to trigger a subacute increase in viral load and therefore of cytokines and viral or microglial products. There is also evidence that the genomic drift shown by HIV can lead to a more neurotrophic or neurovirulent strain. For example, the Johns Hopkins group have shown differences at codons 305 and 329 in the virus recovered from the brains of demented patients with AIDS when contrasted with those from similar but nondemented cases. ${ }^{36}$ It is possible that the reason that dementia affects some but not all patients depends on whether critical mutations occur in their resident HIV strain. A combination of differences in trophism and viral load would then combine to determine the clinical sequelae.

Our study set out to confirm or refute the hypothesis that immunosuppression was critical to the emergence of evidence of CNS disease related to HIV infection itself - that is, excluding those situations where symptoms and signs were demonstrably due to opportunistic infections by known infective agents or to lymphoma. We have previously reported the findings of a neuropsychological test battery in our cohort ${ }^{11}$ which disclosed no evidence of impairment in asymptomatic pre-AIDS HIV infection. Five years on the findings were confirmed with little or no evidence of abnormality in a multimodality assessment protocol. In the present report, the detailed assessments of over 100 men infected with HIV have been compared with those of seronegative subjects from a comparable background. In general the results of other large studies ${ }^{37}$ are confirmed with no consistent evidence from clinical examination, MRI/MRS, EEG, or neuropsychological testing of any impairment in HIV seropositive subjects without AIDS.

The implication of these findings is firstly that, as in this study, at risk though seronegative homosexual men may have subtle signs suggestive of neurological sequelae but these may reflect their lifestyle. Use of opiates and stimulants was confined to one or two persons only but half the group had some exposure to cannabis. Nine of the 32 had a history of syphilis.

The second implication is that theories of the mechanism of HIV associated dementia complex with and without associated myelopathy must take account of the fact that even subtle 
signs of these CNS complications follow rather than precede clinical evidence of immunosuppression. This would support the current hypothesis that viral load, which increases as immunosuppression develops, may be critical, whether through viral products or the production of cytokines by activated macrophages. ${ }^{4}$

Magnetic resonance imaging is in widespread diagnostic use in the investigation and management of HIV related CNS diseases, proving more sensitive than CT in lesion detection for example. ${ }^{19}$ The present study has also disclosed that both visually rated and semiautomated quantitative measurements of cerebral atrophy correlate with the clinical diagnosis of neurological abnormality, particularly of encephalopathy. Changes in white matter detected visually or by relaxometry were correlated with neuropsychological test results independently of the presence of atrophy. This suggests that the impairment in cognition is indeed subcortical and perhaps relates more to encephalitis and leukoencephalopathy than to loss of cortical cells. ${ }^{7}$ Unfortunately MRI cannot always distinguish between changes in white matter due to HIV encephalitis and leukoencephalopathy and the effects of cytomegalovirus infection or non-specific astrocytosis ${ }^{38-40}$ More precise correlation of early cognitive change and underlying pathology is not therefore possible with these data.

Only a subset of the subjects in this longitudinal study had MRS and this may explain the failure to find any clear pattern of abnormality. Data from a large pool of patients from our AIDS wards have suggested that MRS may detect changes in AIDS, even at an asymptomatic stage albeit in those with laboratory evidence of immunosuppression. ${ }^{41}$

Although EEG abnormalities were detected in a few of these subjects they did not seem to be a sensitive indicator of CDC status or to correlate well with clinical and imaging criteria for early encephalopathy associated with atrophy. Others have similarly shown no consistent EEG changes in asymptomatic HIV infection ${ }^{13}$ At a later stage EEG slowing does parallel neurological deterioration. ${ }^{12}$ We have previously reported the results of somatosensory ${ }^{42}$ and long latency event related evoked potentials in this cohort recorded at earlier attendances. ${ }^{43}$ These too showed no definite differences in amplitudes or latencies between those who were seronegative, seropositive, but asymptomatic, and those with early stages of AIDS defined by clinical criteria.

The neuropsychological test battery disclosed significant differences on the overall measure of performance and in three of the tests. In all cases the AIDS group were found to have performed at a significantly poorer level than the other groups. This confirms the view that cognitive decline occurs once patients are immunocompromised and is not apparent in asymptomatic seroposive subjects. ${ }^{37}$ When comparison was made with the other assessments the Rey verbal memory task was associated with the detection of clinical abnormality, a diagnosis of encephalopathy, and of atrophy on imaging. The result of trailmaking $\mathrm{B}$, symbol digit, and non-verbal memory tests correlated with white matter changes. The choice reaction time was more influenced by physical impairment as in neuropathy. The correlation of some tests with changes in white matter is compatible with a subcortical dementia and with results in patients with ischaemic leukoariosis and even in healthy elderly people. $^{44}$

A comparison of the various assessments used suggests that a combination of clinical examination, imaging for atrophy, and a brief neurocognitive test battery should be sufficient to detect early changes in HIV related diffuse CNS disease. This assessment protocol may serve as an indicator of therapeutic response in studies designed to delay the appearance of damage to the CNS. There is some evidence that MRS may also have a role if short term response to intervention (for example, the use of a powerful antiretroviral agent reducing viral load) is the critical issue. ${ }^{456}$ These techniques offer a way of monitoring treatment and offer possible end points in trials of new strategies in the prevention of HIV associated dementia in particular.

This study was supported throughout by the Medical Research Society

1 Snider WD, Simpson DM, Nielsen S. Neurological complications of acquired immune deficiency syndrome: analysis of 80 patients. Ann Neurol 1983;14:403-18.

2 Navia BA, Cho ES, Petito CK, et al. The AIDS dementia Navia BA, Cho ES, Petito CK, et al. The AIDS dem
complex II. Neuropathol Ann Neurol 1986;19:525-35.

3 Sharer LR, Epstein LG, Cho E-S, et al. Pathological features of AIDS encephalopathy in children: evidence for LAV/ HTLV-III infection in brain. Hum Pathol 1986;17:271-84. 4 Royal W, Selnes OA, Concha M, et al. Cerebrospinal fluid HIV-1 p24 antigen levels in HIV-1 related dementia. Ann Neurol 1994:36;32-9.

5 Heyes MP, Brew BJ, Martin A, et al. Quinolinic acid in cerebrospinal fluid and serum in HIV-1 infection: relationship to clinical and neurologic status. Ann Neurol 1992;29:202-

6 Wesselingh SL, Power C, Glass J, et al. Intracerebral cytokine messenger RNA expression in acquired immunodeficiency syndrome dementia. Ann Neurol 1993;33:57582.

7 Everall IP, Glass JD, McArthur J, et al. Neuronal density in the superior frontal and temporal gyri does not correlate with the degree of human immunodeficiency viruswith the degree of human immunodeficiency virus-

8 Post MJD, Tate LG, Quencer RM, et al. CT, MR and Post MJD, Tate LG, Quencer RM, et al. CT, MR and
pathology in HIV encephalitis and meningitis. AfNR Am $\mathcal{f}$ Neuroradiol 1988;158:141-8.

9 Post MJD, Levin BE, Berger JR, et al. Sequential cranial MR findings of asymptomatic and neurologically symptomatic HIV positive subjects. AfNR Am $\mathcal{F}$ Neuroradiol 1992;13: 359-70.

10 Chong WK, Sweeney B, Wilkinson ID, et al. Proton spectroscopy of the brain in HIV infection: correlation with clinical, immunologic, and MR imaging findings Radiology 1993;188: 119-24.

11 McArther JC, Kumar AJ, Johnson DW, et al. Incidental white matter hyperintensities on magnetic resonance imaging in HIV-1 infection. Multicentre AIDS cohort study. fournal of Acquired Immune Deficiency Syndromes 1990;3: 252-9.

12 Tinuper P, de Carolis P, Galeotti M, et al. Electroencephalogram and HIV infection: a prospective study in 100 gram and HIV infection: a prospective study

13 Nuwer MR, Miller EN, Visscher BR, et al. Asymptomatic HIV infection does not cause EEG abnormalities: results from the multicenter AIDS cohort study (MACS). Neurology 1992;42:1214-19.

14 Parisi A, Di Perri G, Strosselli M, et al. Usefulness of computerized electroencephalography in diagnosing, staging,
and monitoring AIDS-dementia complex. AIDS 1989;3: 209-13.

15 Tross S, Price RW, Navia B, et al. Neuropsychological characterization of the AIDS dementia complex: a preliminary report. AIDS 1988;2:81-8.

16 McAllister RH, Harrison MJG, Hearns MV, et al. Neurological and neuropsychological performance in HIV seropositive men without symptoms $f$ Neurol Neurosurg seropositive men without
Psychiatry 1992;55:143-8.

17 Grant I, Hampton Atkinson J, Kesselink JR, et al. Evidence of early central nervous system invovement in the acquired 
immunodeficiency syndrome (AIDS) and other immunodeficiency. Ann Interm Med 1987;107:828-36.

18 Selnes OA, Miller E, McArthur JC, et al. HIV-1 infection: no evidence of cognitive decline during the asymptomatic stages. Neurology 1990;40:204-8.

19 Newman SP, Lunn S, Harrison MJG. Do asymptomatic HIV-seropositive individuals show cognitive deficit? AIDS 1995;9:1211-20.

20 Janssen RS, Cornblath DR, Epstein LG, et al. Nomenclature and research case definitions for neurological manifestations of human immunodeficiency (HIV-1) infection: report of a working group of the American Academy of Neurology AIDS Task Force. Neurology 1991;41:778-85.

21 Newman S, Pugsley W, Klinger L, et al. Neuropsychological consequences of circulatory arrest with hypothermia-a case report. I Clin Exp Neuropsychol 1989;11:529-38.

22 Warrington $\mathrm{E}$, James $M$. An experimental investigation of facial recognition in patients with unilateral cerebral lesions. Cortex 1967;3:317-26.

23 Heaton RK. Wisconsin card sorting manual. Odessa, FL: Psychological Assessment Resources, 1981.

24 Smith A. Symbol digit modalities test, manual. Los Angeles: Smith A. Symbol digit modalities test, man
Western Psychological Services, 1973.

25 Wilkinson ID, Paley MNJ, Hall-Craggs MA, et al. Cerebral Wilkinson ID, Paley MNJ, Hall-Craggs MA, et al. Cerebral
magnetic resonance relaxometry in HIV infection. Mag Res Imaging 1996;14:365-72.

26 Paley MNJ, Chong WK, Wilkinson ID, et al. Cerebrospina fluid-intracranial volume ratio measurements in patients with HIV infection: CLASS image analysis technique. Radiology 1994;190:879-86.

27 Carne CA, Tedder RS, Smith A, et al. Acute encephalopathy coincident with seroconversion for anti-HTLV-III. Lancet 1985;ii: $1206-8$

28 Nogales-Gaete J, Syndulko K, Tortellotte WW. Cerebrospinal fluid (CSF) analyses in HIV-1 primary neurological disease. Ital F Neurol Sci 1992;13:667-83.

29 Sharer LR. Pathology of HIV-1 infection of the central nervous system. F Neuropathol Exp Neurol 1992;51:3-11.

30 Tornatore C, Chandra R, Berger JR, et al. HIV-1 infection of subcortical astrocytes in the pediatric central nervous subcortical astrocytes in the pedia

31 Everall IP, Luthert PJ, Lantos PL. Neuronal loss in the frontal cortex in HIV infection. Lancet 1991;337:1119-21.

32 Wiley CA Masliah E, Morey M, et al. Neocortical damage Wiley CA, Masliah E, Morey M, et al. Neocortical
during HIV infection. Ann Neurol 1991;29:651-7.

33 Genis P, Jett M, Bernton EW, et al. Cytokines and arachidonic acid metabolites produced during human immunodeficiency virus (HIV)-infected macrophageastroglia interactions: implications for the neuropathogenesis of HIV disease. 7 Exp Med 1992;176:1703-18.
34 Budka $\mathrm{H}$, Wiley CA, Kleihuis $\mathrm{P}$, et al. HIV-associated disease of the nervous system: review of nomenclature and proposal for neuropathology-based terminology. Brain Pathol 1991;1:143-52.

35 McArthur JC, Hoover DR, Bacellar H, et al. Dementia in AIDS patients: incidence and risk factors. Neurology 1993; 43:2245-52.

36 Power C, McArthur JC, Johnson RT, et al. Demented and non-demented patients with AIDS differ in brain derived human immunodeficiency virus type 1 envelope sequences. f Virol 1994;68:4643-9.

37 Selnes OA, Miller E, McArthur JC, et al.. HIV-1 infection: no evidence of cognitive decline during the asymptomatic stages. Neurology 1990;40:204-8.

38 Sze G, Brandt-Zawadzki MN, Norman D, et al. The neuroradiology of AIDS Semin Roentgenol 1987;22:42-53.

39 Everall IP, Chong WK, Wilkinson ID, et al. Correlation of MRI and neuropathology in AIDS. $\mathcal{f}$ Neurol Neurosurg Psychiatry 1997;62:92-5.

40 Post MJ, Tate JG, Quencer RM, et al. CT, MR, and pathology in HIV encephalitis and meningitis. AfR Am $\mathcal{F}$ Roentgenol 1988;151:373-80.

41 Wilkinson ID, Miller RF, Miszkiel KA, et al. Cerebral proton magnetic resonance spectroscopy in asymptomatic HIV infection. AIDS 1997;11:289-95.

42 Connolly S, Manji H, McAllister RH, et al. Neurophysiological assessment of peripheral nerve and spinal cord function in asymptomatic HIV-1 infection: results from the UCMSM/Medical Research Council neurology cohort. $f$ Neurol 1995;242:406-11.

43 Connolly S, Manji H, McAllister RH, et al. Long-latency event-related potentials in asymptomatic human immunodeficiency virus type 1 infection Ann Neurol 1994;35:18996.

44 Ylikoski R, Ylikoski A, Erkinjuntii T, et al. White matter changes in healthy elderly persons correlate with attention and speed of mental processing. Arch Neurol 1993;50:81824

45 Vion-Dury J, Nicoli F, Salvan AM, et al. Reversal of brain metabolic alterations with zidovudine detected by proton localised magnetic resonance spectroscopy. Lancet 1995; 345:60-1.

46 Wilkinson ID, Lunn S, Miszkiel KA, et al. Proton MRS and quantitative MRI assessment of the short term neurological response to antiretroviral therapy in AIDS $f$ Neurol Neurosurg Psychiatry 1997;63:477-82. 